\title{
$\infty \sqrt{1}$ Stroke and \\ China Stroke Statistics 2019: a wealth of opportunities for stroke prevention
}

\author{
J David Spence
}

To cite: Spence JD. China Stroke Statistics 2019: a wealth of opportunities for stroke prevention. Stroke \& Vascular Neurology 2020;5: e000529. doi:10.1136/svn-2020-000529

Received 20 July 2020 Accepted 21 July 2020 Published Online First 21 August 2020

\section{Linked}

- http://dx.doi.org/10.1136/ svn-2020-000457

Check for updates

(C) Author(s) (or their employer(s)) 2020. Re-use permitted under CC BY-NC. No commercial re-use. See rights and permissions. Published by BMJ.

Stroke Prevention \& Atherosclerosis Research Centre, Western University, Robarts Research Institute, London, Ontario, Canada

Correspondence to Professor J David Spence; dspence@robarts.ca
The China Stroke Statistics published in this issue of the journal ${ }^{1}$ represent an enormous undertaking. It included data on 3010204 patients who had a stroke admitted in 2018 to 1853 tertiary care hospitals and compiled data from multiple sources on stroke and stroke risk factors in China. The authors and the huge team of workers who must have compiled the statistics are to be commended on this enormous effort. In the report is a wealth of data on what is wrong in China to cause such a high risk of stroke but also a wealth of opportunity to make a difference. The reason this is so important is that $\sim 80 \%$ of strokes are preventable.

\section{STROKE INCIDENCE HIGHEST IN CHINA}

According to the 2016 Global Burden of Disease Study, China had the highest estimated lifetime risk of stroke from age 25 years onwards of up to $39.3 \%$, compared with 22.2\% in Western Europe and 22.4\% in highincome North America. ${ }^{2}$

It is evident from the ratio of strokes to myocardial infarctions in China that hypertension is a major driver of stroke risk. In North America, myocardial infarctions (MI) outnumber strokes, but in China, stroke was historically much more common, though myocardial infarctions have been increasing in recent years. In 2003, in urban China, deaths from stroke were 8.5 times as common as deaths from MI; by 2013, strokes had increased by $26.6 \%$, whereas death from MI increased by $213 \%$, and deaths from stroke were only 2.5 times that of death from MI. This change is no doubt due to increased intake of meat and egg yolk with increasing prosperity in China. ${ }^{3}$

\section{OPPORTUNITIES FOR STROKE PREVENTION ARISING FROM THE DATA \\ Smoking cessation}

In 2018, the prevalence of tobacco smoking in China was $50.5 \%$ of men and $2.1 \%$ of women above age 15 years. Among stroke survivors in China, it was $72.28 \%$ in men and $17.54 \%$ in women. ${ }^{1}$ On a patient basis, there are ways for physicians to help patients quit smoking. A systematic approach such as the Ottawa protocol $^{4}$ is more effective than haphazard approaches; it includes counselling, liberal use of nicotine substitutes and sometimes medication such as varenicline or bupropion. In the Insulin Resistance Intervention After Stroke trial, smoking cessation after stroke was associated with a $34 \%$ reduction of the 5-year risk of stroke and MI or vascular death.$^{5}$ On a population basis, however, interventions by government would be more likely to make a big difference. Banning smoking in public places, preventing sales of tobacco to minors, increasing taxation on tobacco products and printing smoke prevention messages on tobacco packaging are examples of such interventions that can make a difference.

\section{Reduction of sodium intake}

The report says 'The average daily salt intake among Chinese adults $\geq 18$ years of age was $10.5 \mathrm{~g}$ from 2010-2012, which is lower than $13.9 \mathrm{~g}$ in 1992 and $12.0 \mathrm{~g}$ in 2002. The recommended amount of daily salt intake as per the Chinese Dietary Guidelines is $6 \mathrm{~g}$. As such, the average intake among Chinese adults in 2012 was still $75.0 \%$ higher than the recommended value from 2010 to 2012'. However, in a country where hypertension is a major cause of stroke, it is a mistake to aim for a daily intake of $6 \mathrm{~g}$ per day of salt. Lower salt intakes reduce blood pressure, particularly in patients with higher blood pressure. A more effective target salt intake would be $\sim 3$ g per day. This would require a major societal change. Substituting potassium for part of the sodium in table salt, reducing the salt content of soya sauce, using more vinegar, spices and hot peppers would be approaches that could help. Salt intake is a vicious circle: a high salt intake downregulates salt taste buds on the tongue, so a salty taste is not appreciated, resulting in addition of more salt. It can help to educate patients that within $\sim 3$ weeks of reducing their salt intake, the salt taste buds upregulate (receptor 
upregulation), so they will begin to taste the salt in foods containing less salt.

\section{Increasing intake of whole grains}

A recent study of national dietary guidelines concluded that the dietary change that would have the biggest effect on reduction of non-communicable diseases, with the greatest reduction of greenhouse gases, would be to increase intake of whole grains. ${ }^{6}$ In China, the biggest effect would probably result from switching from polished rice to brown rice. Again, this would represent a major cultural change.

\section{Better treatment of hypertension}

Among stroke survivors, $83.71 \%$ of men and $84.89 \%$ of women had hypertension. ${ }^{1}$

There have been major problems with treatment of hypertension in China. Lu et $a l^{7}$ reported that only $36 \%$ of hypertensives are aware of it, only $22.9 \%$ are on treatment and only $5.7 \%$ are controlled. Above age 65 years, $\sim 60 \%$ of the population are hypertensive, and the control rates are very low. ${ }^{7}$

Much improvement is attainable at low cost by increasing the use of diuretics, particularly given the very high salt intake in China. Su et al reported from a nationwide survey that only $4.5 \%$ of hypertensive patients were prescribed diuretics. In part this may be due to lack of appropriate medications in pharmacies. Only $32.7 \%$ of pharmacies in China stocked high-value medications for hypertension, and only $11.2 \%$ of all prescriptions for hypertension were high-value medications. ${ }^{8}$

In a recent randomised trial aiming to control blood pressure to target systolic blood pressure $<150,<140$ and $<130 \mathrm{~mm} \mathrm{Hg},{ }^{9}$ the protocol specified that initial therapy for all participants was a tablet of therapy was a daily oral dose of one tablet of enalapril $10 \mathrm{mg}$ and folic acid $0.8 \mathrm{mg}$. 'Other drugs, including calcium-channel blockers. (CCBs) (amlodipine preferred), diuretics (hydrochlorothiazide preferred), and $\beta$-blockers, were allowed, in order to achieve the SBP target'. In that study, the percentage of patients who received diuretic was $\sim 20 \%$ in the $<150 \mathrm{~mm} \mathrm{Hg}$ group, $30 \%$ in the $<140 \mathrm{~mm} \mathrm{Hg}$ group and $40 \%$ in the $<130 \mathrm{~mm} \mathrm{Hg}$ group. This illustrates the opportunity for improved blood pressure control by increasing use of diuretics.

In 2017, I reviewed opportunities for improving blood pressure control in China. ${ }^{10}$ "Causes of resistant hypertension include 1) non-compliance; (2) consumption of substances that aggravated hypertension, such as excess salt, alcohol, licorice, decongestants and oral contraceptives; (3) therapeutic inertia (failure to intensify therapy when target blood pressures are not achieved); and (4) diagnostic inertia (failure to investigate the cause of resistant hypertension) ${ }^{\prime} .{ }^{10}$

A major opportunity to improve blood pressure control in patients with resistant hypertension is 'diagnostic inertia" Physiologically individualised therapy based on phenotyping with plasma aldosterone and renin markedly improves blood pressure control. ${ }^{11}$ A Chinese study ${ }^{12}$ reported that interpretation of the aldosterone/renin phenotype must take into account the class of hypertensive drug being used at the time of blood sampling. It is most informative to measure plasma aldosterone and renin in a stimulated condition (when the patient is taking diuretic, ACE inhibitor or angiotensin receptor blocker).

In conclusion, there is much that can be done to reduce the enormous burden of stroke in China. Reducing smoking and salt intake, and improving blood pressure control, could probably reduce stroke by half. ${ }^{13}$ The cost of stroke is so high in China that determined efforts to do so should be undertaken.

Contributors I wrote this editorial.

Funding No funding was received to support this editorial from any funding agency in the public, commercial or not-for-profit sectors.

Competing interests None declared.

Patient consent for publication Not required.

Provenance and peer review Commissioned; internally peer reviewed.

Open access This is an open access article distributed in accordance with the Creative Commons Attribution Non Commercial (CC BY-NC 4.0) license, which permits others to distribute, remix, adapt, build upon this work non-commercially, and license their derivative works on different terms, provided the original work is properly cited, appropriate credit is given, any changes made indicated, and the use is non-commercial. See: http://creativecommons.org/licenses/by-nc/4.0/.

ORCID iD

J David Spence http://orcid.org/0000-0001-7478-1098

\section{REFERENCES}

1 China stroke statistics 2019: a report from the National center for healthcare quality management in neurological diseases, China national clinical research center for neurological diseases, the Chinese stroke association, National center for chronic and noncommunicable disease control and prevention, Chinese center for disease control and prevention, and Institute for global neuroscience and stroke collaborations. Stroke Vasc Neurol. In Press 2020.

2 GBD 2016 Lifetime Risk of Stroke Collaborators, Feigin VL, Nguyen $\mathrm{G}$, et al. Global, regional, and Country-Specific lifetime risks of stroke, 1990 and 2016. N Engl J Med 2018;379:2429-37.

3 Spence JD. Diet for stroke prevention. Stroke Vasc Neurol 2018;3:44-50.

4 Reid RD, Mullen K-A, Slovinec D'Angelo ME, et al. Smoking cessation for hospitalized smokers: an evaluation of the "Ottawa Model". Nicotine Tob Res 2010;12:11-18.

5 Epstein KA, Viscoli CM, Spence JD, et al. Smoking cessation and outcome after ischemic stroke or TIA. Neurology 2017;89:1723-9.

6 Springmann M, Spajic L, Clark MA, et al. The healthiness and sustainability of national and global food based dietary guidelines: modelling study. BMJ 2020;370:m2322.

7 Lu J, Lu Y, Wang X, et al. Prevalence, awareness, treatment, and control of hypertension in China: data from 1.7 million adults in a population-based screening study (China peace million persons project). Lancet 2017;390:2549-58.

8 Su M, Zhang Q, Bai X, et al. Availability, cost, and prescription patterns of antihypertensive medications in primary health care in China: a nationwide cross-sectional survey. Lancet 2017;390:2559-68.

9 Huang X, Liu L, Song Y, et al. Achieving blood pressure control targets in hypertensive patients of rural China - a pilot randomized trial. Trials 2020;21:515.

10 Spence JD. Controlling resistant hypertension. Stroke Vasc Neurol 2018;3:69-75.

11 Akintunde A, Nondi J, Gogo K, et al. Physiological phenotyping for personalized therapy of uncontrolled hypertension in Africa. Am J Hypertens 2017;30:923-30.

12 Huang X, Li J, Liu L, et al. Interpreting stimulated plasma renin and aldosterone to select physiologically individualized therapy for resistant hypertension: importance of the class of stimulating drugs. Hypertens Res 2019;42:1971-8.

13 Spence JD. Antihypertensive drugs and prevention of atherosclerotic stroke. Stroke 1986;17:808-10. 